\title{
Antibiotic Susceptibility Patterns and Prevalence of Streptococcus Agalactiae Rectovaginal Colonization Among Pregnant Women in Iran
}

\author{
Mina Dashtizade ${ }^{10}$ Mohammad Reza Zolfaghari ${ }^{10}$ \\ ${ }^{1}$ Department of Microbiology, Qom Branch, Islamic Azad University, \\ Qom, Iran \\ 2 Birjand Infectious Diseases Research Center, Department of \\ Microbiology, Faculty of Medicine, Birjand University of Medical \\ Sciences, Birjand, Iran \\ ${ }^{3}$ Department of Microbiology, Faculty of Medicine, Kashan University \\ of Medical Sciences, Kashan, Iran
}

Masoud Yousefi $2 \odot$

Ali Nazari-Alam 3 (1)

Address for correspondence Ali Nazari-Alam, Assistant Professor,
Department of Microbiology, Faculty of Medicine, Kashan University
of Medical Sciences, Kashan, Iran (e-mail: nazarialam-a@kaums.ac.ir).

Rev Bras Ginecol Obstet 2020;42(8):454-459.

\begin{abstract}
Keywords

- Streptococcus agalactiae

- pregnant women

- antibiotic resistance

- risk factors

- polymerase chain reaction

Objective Streptococcus agalactiae is an important pathogen in neonates and pregnant women. Neonatal invasive infections due to $S$. agalactiae are life-threatening and preventive strategies for this challenge of human have become a concern. The aim of the present study was to determine the prevalence of rectovaginal colonization, related risk factors and antibiotic resistance pattern of S. agalactiae among pregnant women in Iran.

Methods The present study was performed on 240 pregnant women. Vaginal and rectal swabs were obtained from all of the women and then were transferred to the laboratory. The isolation and identification of $S$. agalactiae was performed by standard microbiological tests and polymerase chain reaction (PCR) assay. The antimicrobial susceptibility patterns of the isolates were determined by the Kirby-Bauer disk diffusion. Polymerase chain reaction was used to detect ermB and mefA genes in erythromycin-nonsusceptible isolates.

Results Out of 240 pregnant women, 16 cases (6.7\%) were colonized by S. agalactiae. There is no significant association between demographic-obstetric factors and maternal S. agalactiae colonization in the pregnant women. Linezolid, vancomycin and ampicillin were the most effective antibiotics against $S$. agalactiae. The ermB gene was present in $6(35.29 \%)$ S. agalactiae isolates. However, the mefA gene was not detected in any of the isolates.

Conclusion Given the relatively significant prevalence of $S$. agalactiae colonization in the pregnant women in the present study and the risk of serious neonatal infections, the screening of pregnant mothers for the bacteria seems necessary. Our findings highlight the importance of appropriate antibiotic prophylaxis during pregnancy for the prevention of early onset $S$. agalactiae-neonatal infection and comorbidity.
\end{abstract}

received

January 21, 2020

accepted

March 10, 2020
DOI https://doi.org/

$10.1055 / \mathrm{s}-0040-1710299$.

ISSN 0100-7203.
Copyright $\odot 2020$ by Thieme Revinter

Publicações Ltda, Rio de Janeiro, Brazil
License terms

(c) (i) 


\section{Introduction}

Streptococcus agalactiae (Group B Streptococcus [GBS]) is considered as the dominant pathogen in causing septicemia and meningitis in infants $<3$ months old. Neonatal invasive infections due to $S$. agalactiae are life-threatening and preventive strategies for this challenge of human have become a concern. ${ }^{1,2}$

As an important opportunistic human pathogen, GBS can be colonized in the rectovaginal area of women and subsequently transmitted to the neonates in the womb or during labor. The rate of GBS colonization among pregnant women varies with ethnic group, marital status, number of deliveries, geographic area and age. ${ }^{3,4}$ It is noteworthy that $\sim$ between 10 and $30 \%$ of women during pregnancy are colonized with S. agalactiae in the vagina and $60 \%$ of their infants acquire the bacteria through the birth canal. ${ }^{5,6}$ Identification of maternal GBS colonization during pregnancy is important for taking preventive measures to control neonatal diseases. ${ }^{1,2}$

The Centers for Disease Control and Prevention (CDC), in order to reduce the incidence of neonatal GBS diseases, recommends the use of intrapartum antibiotic prophylaxis in pregnant women with rectovaginal colonization of GBS. However, the widespread adoption of intrapartum antibiotic prophylaxis for prevention of invasive early-onset GBS disease has led to an increase in concerns regarding the emergence of antibiotic resistance among GBS strains. So, the antibacterial susceptibility data of maternal colonizing GBS strains are essential to selective intrapartum antibiotic prophylaxis and minimize the emergence of bacterial resistance, which is causing increasing numbers of treatment failures. $^{7-9}$

Given the importance of universal screening of mothers for rectovaginal GBS colonization and achieving appropriate intrapartum antibiotic prophylaxis for all screen-positive women to prevent early-onset GBS-related diseases, the aim of the present study was to investigate the prevalence and related risk factors of GBS rectovaginal colonization in pregnant women as well as the antimicrobial susceptibility pattern of the isolates.

\section{Methods}

\section{Study Population and Sampling Procedure}

The present cross-sectional study was conducted among 240 pregnant women with gestational age of between 35-37 weeks referred to the Kashan Shahid Beheshti Hospital from
January to September 2017. After receiving permission from the Ethics Committee of Kashan University of Medical Sciences (IR.KAUMS.PEC.1394.151), sociodemographic and clinical data were collected using a structured questionnaire.

Samples were taken using two sterile cotton swabs from the vaginal and rectal area according to the CDC and American College of Obstetricians and Gynecologists (ACOG) guidelines, ${ }^{9,10}$ and inoculated directly into Todd-Hewitt broth (THB) (Merck \& Co., Kenilworth, NJ, USA) supplemented with gentamicin $(8 \mu \mathrm{g} / \mathrm{ml})$ and nalidixic acid $(15 \mu \mathrm{g} / \mathrm{ml})$ (Sigma Aldrich, St. Louis, Missouri, USA), then were immediately transported to the microbiology laboratory within 2 hours of collection.

\section{Phenotypic Identification of Group B Streptococci}

The broth media were incubated for between 18 and 24 hours at between $35-37^{\circ} \mathrm{C}$ and inoculated on $5 \%$ sheep blood agar (SBA) (Merck \& Co., Kenilworth, NJ, USA) and incubated overnight in 5\% CO2 atmosphere for between 1824 hours. Finally, suspected GBS colonies (pink colonies, with narrow $\beta$-hemolysis) were identified by conventional microbiological and biochemical methods, including Gram stain, catalase test, bacitracin and sulfamethoxazole-trimethoprim (SXT) susceptibility tests, hippurate hydrolysis test (Mast Group Ltd, Bootle, UK), and Christie, Atkins, and MunchPeterson (CAMP) test. ${ }^{9,11}$

\section{PCR Confirmation of GBS Isolates}

The PCR assays were used to confirm the diagnosis of GBS isolates by detecting the dlts target gene (-Table $\mathbf{1}$ ). Genomic DNA was extracted from pure cultures of the strains using High Pure PCR Template Preparation Kit (Roche, Basel, Switzerland) according to the instructions of the manufacturer. Polymerase chain reaction was conducted on the summation of all volumes consisting of $25 \mu \mathrm{L}(12.5 \mu \mathrm{L}$ of $2 \times$ Hot Star Taq Master Mix, $1 \mu \mathrm{L}$ of the DNA template, $1 \mu \mathrm{L}$ of each primer [ $50 \mathrm{pmol} / \mu \mathrm{l}]$ and $9.5 \mu \mathrm{L}$ of ddH2O) using the Hot Star Taq Master Mix kit (SinaClon, Tehran, Iran). Settings for the reaction were as follows: initial denaturation step at $94^{\circ} \mathrm{C}$ for 5 minutes; 35 amplification cycles each for 30 seconds at $94^{\circ} \mathrm{C}, 30$ 1 minute at $55^{\circ} \mathrm{C}$ and 1 minute at $72^{\circ} \mathrm{C}$. This was followed by an additional extension step of 10 minutes at $72^{\circ} \mathrm{C}$. The PCR product of the ditS gene was electrophoresed on $1 \%$ agarose gel containing $1 \mathrm{x}$ RedSafe DNA stain (Intron Biotechnology, Seoul, South Korea).

Table 1 Target genes and their primers used in the present study

\begin{tabular}{lllll}
\hline Primer & Sequence $\left(5^{\prime}-3^{\prime}\right)$ & Products sizes $(\mathrm{bp})$ & Annealing $\left({ }^{\circ} \mathrm{C}\right)$ & Ref. \\
\hline$d i t s$ & $\begin{array}{l}\text { Fw- AGGAATACCAGGCGATGAAC } \\
\text { Rv- TGCTCTAATTCTCCCCTTATGGC }\end{array}$ & 952 & 55 & $(7)$ \\
ermB & $\begin{array}{l}\text { Fw- CGACGAAACTGGCTAAAATA } \\
\text { Rv- AATTGCTGAATCGAGACTTG }\end{array}$ & 331 & 58 & Present Study \\
mefA & Fw- GGTGTGCTAGTGGATCGTC & 188 & 53 & Present Study \\
& Rv- GTAACCGCATTGAGAGCCG & & & \\
\hline
\end{tabular}




\section{Antibiotic Susceptibility Testing}

The antibiotic resistance profile of the isolates was determined by the Kirby-Bauer disk-diffusion method on MullerHinton agar (MHA) (Merck \& Co., Kenilworth, NJ, USA) with $5 \%$ sheep's blood, and the results were interpreted according to the Clinical and Laboratory Standards Institute (CLSI) guidelines. ${ }^{12}$ The antimicrobial agents (Mast Group Ltd, Bootle, UK) tested in the present study included ampicillin $(10 \mu \mathrm{g})$, vancomycin $(30 \mu \mathrm{g})$, erythromycin $(15 \mu \mathrm{g})$, clindamycin $(2 \mu \mathrm{g})$, levofloxacin $(5 \mu \mathrm{g})$, chloramphenicol $(30 \mu \mathrm{g})$, cefepime (30 $\mu \mathrm{g})$, and linezolid $(30 \mu \mathrm{g})$. Streptococcus pneumoniae ATCC 49619 was used for quality control of antibiotic susceptibility testing.

\section{Detection of Erythromycin Resistance Genes}

In the present study, due to the high rates of resistance to erythromycin in GBS, the mechanism of resistance to this antibiotic was studied with detection of ermB and mefA genes by PCR. The PCR was performed in the total volume of $25 \mu \mathrm{l}(12.5 \mu \mathrm{l}$ of $2 \mathrm{x}$ Hot Star Taq Master Mix, $1 \mu \mathrm{l}$ of the DNA template, $1 \mu \mathrm{l}$ of each primer [50 pmol/ $\mu \mathrm{l}]$ and $9.5 \mu \mathrm{l}$ of ddH2O) utilizing the Hot Star Taq Master Mix kit (SinaClon, Tehran, Iran). DNA amplification was performed in a thermocycler (Eppendorf, Hamburg, Germany) with an initial denaturation step at $95^{\circ} \mathrm{C}$ for 5 minutes, 30 amplification cycles each with 30 seconds at $95^{\circ} \mathrm{C} ; 30$ seconds at different temperatures for the various genes ( - Table 1 ); and $40 \mathrm{sec}-$ onds at $72^{\circ} \mathrm{C}$, followed by an additional extension step of 7 minutes at $72^{\circ} \mathrm{C}$. The amplified products were electrophoresed on 1.5\% gel agarose containing 1x RedSafe DNA stain (Intron Biotechnology, Seoul, South Korea). Sequencing of amplicons was done by the Bioneer Company (Daejeon, South Korea). The BLAST program from the national center for biotechnology information (NCBI) Web site (http://www. ncbi.nlm.nih.gov/BLAST) was used to analyze the nucleotide sequences.

\section{Statistical Analysis}

The data were analyzed with the Pearson chi-squared and the Fisher exact tests, using SPSS Statistics for Windows, Version 21.0 (IBM Corp. Armonk, NY, USA), to evaluate the statistical significance of associations between potential variables. P-values $<0.05$ were considered to be significant.

\section{Results}

In the present study, a total of 240 pregnant women (from 35 to 37 weeks of gestation) were enrolled. The mean age of the participants was $26.9 \pm 4.41$ years old, with the youngest being 16 and the oldest 45 years old.

\section{GBS Colonization and Related Risk Factors}

The results indicated that 16 (6.7\%) among the 240 pregnant women screened were colonized by $S$. agalactiae in their rectovaginal area. Of the 16 colonized patients, 8 had strains cultured only from vaginal swabs (50\%), while 5 had strains isolated only from rectal swabs (31.25\%) and another 3 had
Table 2 Association between sociodemographic factors and GBS colonization among pregnant women

\begin{tabular}{llll}
\hline Variables & $\begin{array}{l}\text { Frequency } \\
\mathrm{n}(\%)\end{array}$ & $\begin{array}{l}\text { Culture } \\
\text { positive } \\
\mathbf{n}(\%)\end{array}$ & p-value \\
\hline $\begin{array}{l}\text { Age group } \\
\text { (years old) }\end{array}$ & & 0.494 \\
$20 \leq$ & $12(5)$ & $2(16.7)$ & \\
$21-30$ & $116(48.3)$ & $6(5.2)$ & \\
$31-35$ & $72(30)$ & $5(6.9)$ & \\
$36-45$ & $40(16.7)$ & $3(7.5)$ & \\
Education & $53(22.1)$ & $3(5.7)$ & \\
Illiterate & $35(14.6)$ & $2(5.7)$ & \\
Pre-high school & $93(38.8)$ & $6(6.5)$ & \\
High school & $59(24.6)$ & $5(8.5)$ & \\
College & & & \\
Occupation & $218(90.8)$ & $15(6.9)$ & \\
Housewife & $22(9.2)$ & $1(4.5)$ & \\
Employed & & $15(7)$ & \\
Ethnicity groups & $214(89.2)$ & $1(3.8)$ & \\
Iranian & $26(10.8)$ & & \\
Afghan & & & \\
\hline
\end{tabular}

strains isolated simultaneously from both the vaginal and rectal swabs (18.75\%). Overall, the GBS vaginal and rectal colonization rates were $4.58 \%$ and $3.33 \%$ respectively, while concomitant rectovaginal colonization rate was reported as $1.25 \%$. The sociodemographic and pregnancy-related characteristics of the pregnant women and their relationship with maternal rectovaginal colonization of GBS are summarized in - Tables $\mathbf{2}$ and $\mathbf{3}$. Statistical analysis results showed that there was no significant association between demographic-obstetric factors and colonization of the maternal rectovaginal region with GBS.

\section{Antibiotic Susceptibility}

The results of antimicrobial susceptibility testing also showed that GBS isolates isolated from pregnant women was susceptible mainly to linezolid (100\%), vancomycin (100\%), and ampicillin (89.5\%) (-Table 4). The intermediate antimicrobial resistance of GBS was $15.8 \%$ against erythromycin, $10.5 \%$ against ampicillin and levofloxacin, and 5.3\% against clindamycin. It is noteworthy that the highest antibiotic resistance of GBS was related to erythromycin (73.7\%).

\section{Prevalence of Erythromycin Resistance Genes}

In the present study, the mechanism of resistance to erythromycin in the GBS isolates was studied with detection of ermB and mefA genes. The ermB gene was identified in 6 (35.29\%) erythromycin nonsusceptible isolates. However, the mefA gene was not detected in any of the isolates. 
Table 3 Association between pregnancy-related characteristics and Group B Streptococcus colonization among pregnant women

\begin{tabular}{|c|c|c|c|}
\hline Variables & $\begin{array}{l}\text { Frequency } \\
\mathrm{n}(\%)\end{array}$ & $\begin{array}{l}\text { Culture } \\
\text { positive } \\
\mathrm{n}(\%)\end{array}$ & p-value \\
\hline Gravidity & & & 0.137 \\
\hline Primigravida & 79 (32.9) & $8(10.1)$ & \\
\hline Multigravida & $161(67.1)$ & $8(5)$ & \\
\hline Type of delivery & & & 0.251 \\
\hline Without delivery & $77(32.1)$ & $8(10.4)$ & \\
\hline Vaginal & $86(35.8)$ & $5(5.8)$ & \\
\hline Cesarean & $77(32.1)$ & $3(3.9)$ & \\
\hline History of Abortion & & & 0.155 \\
\hline Yes & 67 (27.9) & $2(3)$ & \\
\hline No & $173(72.1)$ & $14(8.1)$ & \\
\hline Contraceptive methods & & & 0.777 \\
\hline None & $45(18.8)$ & $5(11.1)$ & \\
\hline Withdrawal & $124(51.7)$ & $6(4.8)$ & \\
\hline Condom & $51(21.3)$ & $4(7.8)$ & \\
\hline DMPA* injection & $16(6.7)$ & $1(6.3)$ & \\
\hline $\mathrm{OCP}^{* *}$ & $2(0.8)$ & $0(0)$ & \\
\hline IUD $D^{* * *}$ & $2(0.8)$ & $0(0)$ & \\
\hline Vaginal infection & & & 0.752 \\
\hline Yes & $99(41.3)$ & $6(6.1)$ & \\
\hline No & $141(58.8)$ & $10(7.1)$ & \\
\hline
\end{tabular}

Abbreviations: DMPA, depomedroxyprogesterone acetate; IUD, intrauterine device; OCP, oral contraceptive pills.

Table 4 Antimicrobial susceptibility pattern of Group B Streptococcus isolates from pregnant women

\begin{tabular}{llll}
\hline Antibiotics & $\begin{array}{l}\text { Susceptible } \\
(\%)\end{array}$ & $\begin{array}{l}\text { Intermediate } \\
(\%)\end{array}$ & $\begin{array}{l}\text { Resistant } \\
(\%)\end{array}$ \\
\hline Erythromycin & $2(10.5)$ & $3(15.8)$ & $14(73.7)$ \\
Clindamycin & $8(42.1)$ & $1(5.3)$ & $10(52.6)$ \\
Ampicillin & $17(89.5)$ & $2(10.5)$ & $0(0)$ \\
Chloramphenicol & $11(57.9)$ & $0(0)$ & $8(42.1)$ \\
Levofloxacin & $13(68.4)$ & $2(10.5)$ & $4(21.1)$ \\
Cefepime & $13(68.4)$ & $0(0)$ & $6(31.6)$ \\
Linezolid & $19(100)$ & $0(0)$ & $0(0)$ \\
Vancomycin & $19(100)$ & $0(0)$ & $0(0)$ \\
\hline
\end{tabular}

\section{Discussion}

In the last few decades, GBS has gained importance due to its implication in adverse obstetric outcomes, and its ability to cause serious neonatal infections. Epidemiological studies have revealed that GBS-colonized pregnant women are $>25$ times more likely to deliver infants with early-onset GBS disease. ${ }^{13,14}$
In the present study, the overall prevalence of GBS colonization among pregnant women was found to be 6.7\%. This finding was slightly lower than many other reports in $\operatorname{Iran}^{15-17}$ and other developing countries such as Ethiopia (7.2\%), Turkey (8\%), China (7.1\%) and Korea $(8.3 \%),{ }^{13,18-20}$ but higher than those reported in India (2.3\%) and Taiwan (6.2\%). ${ }^{3,21}$ However, there are reports of higher rates of GBS colonization compared with our study from Tanzania (23\%), Taiwan (21.8\%) and Brazil (28.4\%). ${ }^{14,22,23}$ These disparities could be explained by the fact that rates of maternal GBS colonization during pregnancy varies in the worldwide population, possibly due to differences in the studied populations (in terms of age, ethnic group, socioeconomic status, sexual behavior and geographic areas), method of sample collection and the diagnostic techniques. It is noteworthy that in the present study the GBS vaginal and rectal colonization rates were $4.58 \%$ and $3.33 \%$, respectively, while concomitant rectovaginal colonization rate was reported as $1.25 \%$. This finding was almost similar with other studies $3,7,14$ and reveals that multisite swabbing may be important in identifying GBS colonization.

Knowledge about the risk factors associated with GBS colonization during pregnancy can be important in reducing the incidence of maternal GBS infections and related neonatal morbidity and mortality. ${ }^{24,25}$ The results of our study showed that there is no significant association between demographicobstetric factors and maternal GBS colonization in pregnant women. Similar findings have been reported in studies conducted elsewhere. ${ }^{24,26-28}$ However, in most other studies, the GBS colonization rate has been associated with some sociodemographic and pregnancy-related characteristics of the pregnant women. ${ }^{3,5,14,16}$ This might be due to the small sample size in the present study. Finally, it was noteworthy in our study that primigravida women were more often associated with GBS colonization, though it was not statistically significant. Similar findings have been reported in studies from Ethiopia, Nigeria, Brazil and India. ${ }^{5,24,25,29,30}$ However, in other studies, the GBS colonization rate was significantly higher in multigravida compared with primigravida women.,20,31 This difference may be due to geographical variation and shows that further studies are needed to confirm the correlation between gravidity and GBS colonization among pregnant women in different geographical locations.

Chemoprophylaxis remains the most effective means to prevent GBS maternal and neonatal infections. ${ }^{9,13}$ The GBS strains isolated in the present study showed higher susceptibility to linezolid, vancomycin, and ampicillin. These results are consistent with the $\mathrm{CDC}$ clinical guidelines for the use of penicillin and ampicillin as the drugs of choice in prevention or treatment of GBS infections. ${ }^{5,24}$ Furthermore, similar results were reported by other studies with high susceptibility rates of GBS strains to amoxicillin, linezolid and vancomycin. ${ }^{7,32,33}$ It is noteworthy that clindamycin and erythromycin were recommended as antibiotic alternatives for penicillin-allergic women at high risk for anaphylaxis. However, recent reports had raised global concerns about increasing emergence of antimicrobial resistance to these antibiotics in GBS isolates. In the present 
study, the rates of resistance to erythromycin and clindamycin were reported as $73.7 \%$ and $52.6 \%$, respectively. However, the erythromycin resistance rate among GBS isolates in the present study was relatively higher when compared with other studies in Iran, ${ }^{34-36}$ but the high rates of resistance to erythromycin in GBS were reported in China (92.5\% and 84.6\%), Iraq (58.6\%) and the USA (50.7\%). ${ }^{37-40}$ Furthermore, high resistance rates of GBS strains to clindamycin were reported from Iran (92.2\%) and other countries such as China (55.7\% and 87.5\%), Iraq (45.6\%) and Italy (32.20\%). ${ }^{19,37,39,41}$ It is noteworthy that the high rate of erythromycin and clindamycin resistance in GBS strongly supports the $\mathrm{CDC}$ recommendations for susceptibility testing of GBS isolates before initiating prophylaxis with erythromycin or clindamycin.

Finally, the results of the present study showed that the ermB gene was present in $35.29 \%$ of GBS erythromycinnonsusceptible isolates. However, the mefA gene was not detected in any of the isolates. Similar findings have been reported in other studies, in which the methylation of target encoded by ermB genes was one of the commonest mechanisms of resistance to erythromycin in GBS isolates. ${ }^{23,42}$ In addition, in some studies similar to our study, the mefA gene has not been identified in erythromycin-resistant GBS isolates. $^{23,43}$ This result implies that there are additional mechanisms involved with erythromycin resistance, which require further investigation.

\section{Conclusion}

Given the relatively significant prevalence of $S$. agalactiae colonization in the pregnant women of the present study and the risk of serious neonatal infections, the screening of pregnant mothers for the bacteria seems necessary. Our findings highlight the importance of appropriate antibiotic prophylaxis during pregnancy for the prevention of early onset $S$. agalactiae-neonatal infection and comorbidity. It is noteworthy, considering the increasing concern about emergence of antimicrobial resistance to erythromycin and clindamycin as antibiotic alternatives in GBS isolates, that the susceptibility testing of the isolates before initiating prophylaxis with these antibiotics is recommended. Finally, further studies are needed to assess the correlation between different risk factors and maternal GBS colonization during pregnancy in various geographical locations.

\section{Contributions}

Nazari-Alam A. and Zolfaghari M. R. designed the study, collected the data, and revised the manuscript. Dashtizade $M$. collected the data and revised the manuscript. Yousefi M. wrote the draft manuscript and edited the paper. All authors read and approved the final manuscript.

\section{Conflict of Interests}

The authors have no conflict of interests to declare.

\section{Acknowledgments}

This research was supported by the Islamic Azad University, Qom, Iran. The authors would like to express their deepest gratitude to the microbiology laboratory staff of the Kashan University of Medical Sciences, Kashan, Iran.

\section{References}

1 Le Doare K, Heath PT. An overview of global GBS epidemiology. Vaccine. 2013;31(Suppl 4):D7-D12. Doi: 10.1016/j.vaccine.2013. 01.009

2 Teatero S, Ferrieri P, Martin I, Demczuk W, McGeer A, Fittipaldi N. Serotype distribution, population structure and antimicrobial resistance of Group B Streptococcus strains recovered from colonized pregnant women. J Clin Microbiol. 2017;55(02):412-422. Doi: 10.1128/JCM.01615-16

3 Sharmila V, Joseph NM, Arun Babu T, Chaturvedula L, Sistla S. Genital tract group B streptococcal colonization in pregnant women: a South Indian perspective. J Infect Dev Ctries. 2011;5 (08):592-595. Doi: 10.3855/jidc. 1551

4 Kolter J, Henneke P. Codevelopment of microbiota and innate immunity and the risk for group B streptococcal disease. Front Immunol. 2017;8:1497. Doi: 10.3389/fimmu.2017.01497

5 Assefa S, Desta K, Lema T. Group B streptococci vaginal colonization and drug susceptibility pattern among pregnant women attending in selected public antenatal care centers in Addis Ababa, Ethiopia. BMC Pregnancy Childbirth. 2018;18(01):135. Doi: 10.1186/s12884-018-1791-4

6 YookJH, Kim MY, Kim EJ, Yang JH, Ryu H-M, Oh KY, et al. Risk factors associated with group B streptococcus resistant to clindamycin and erythromycin in pregnant korean women. Infect Chemother. 2013; 45(03):299-307. Doi: 10.3947/ic.2013.45.3.299

7 Nkembe NM, Kamga HG, Baiye WA, Chafa AB, Njotang PN. Streptococcus agalactiae prevalence and antimicrobial susceptibility pattern in vaginal and anorectal swabs of pregnant women at a tertiary hospital in Cameroon. BMC Res Notes. 2018;11(01): 480. Doi: 10.1186/s13104-018-3589-x

8 Taylor JK, Hall RW, Dupre AR. The incidence of group B streptococcus in the vaginal tracts of pregnant women in central Alabama. Clin Lab Sci. 2002;15(01):16-17

9 Verani JR, McGee L, Schrag SJ; Division of Bacterial Diseases, National Center for Immunization and Respiratory Diseases, Centers for Disease Control and Prevention (CDC). Prevention of perinatal group B streptococcal disease-revised guidelines from CDC, 2010. MMWR Recomm Rep. 2010;59(RR-10):1-36

10 Committee Opinion No. 485: prevention of early-onset group B streptococcal disease in newborns: correction. Obstet Gynecol. 2018;131(02):397. Doi: 10.1097/AOG.0000000000002466

11 Luce E. Koneman's color atlas and textbook of diagnostic microbiology, 6th edition [book review]. Plast Reconstr Surg. 2010;125 (01):414-415. Doi: 10.1097/01.prs.0000358868.74684.60

12 Clinical and Laboratory Standards Institute. Performance Standards for Antimicrobial Susceptibility Testing. 27th ed. Wayne: CLSI; 2017 (CLSI Supplement M100)

13 Woldu ZL, Teklehaimanot TG, Waji ST, Gebremariam MY. The prevalence of Group B Streptococus recto-vaginal colonization and antimicrobial susceptibility pattern in pregnant mothers at two hospitals of Addis Ababa, Ethiopia. Reprod Health. 2014;11 (01):80. Doi: 10.1186/1742-4755-11-80

14 Melo SCCS, Costa AB, Silva FTRD, Silva NMMG, Tashima CM, Cardoso RF, et al. Prevalence of Streptococcus agalactiae colonization in pregnant women from the 18th Health Region of Paraná State. Rev Inst Med Trop São Paulo. 2018;60:e2. Doi: 10.1590/ s1678-9946201860002

15 Mashouf RY, Mousavi SM, Rabiee S, Alikhani MY, Arabestani MR. Direct identification of Streptococcus agalactiae in vaginal colonization in pregnant women using polymerase chain reaction. J Compr Pediatr.. 2014;5(04):e23339. Doi: 10.17795/compreped-23339

16 Akbarian Rad Z, Haghshenas Mojaveri M, Esmaeilzadeh S, Firouzjahi A, Laegh M, Khafri S, et al. Colonization of rectovaginal Escherichia 
coli and group B streptococci in mothers and on infants' body surface and their related risk factors. Caspian J Pediatr.. 2016;2(02): 148-52. Doi: 10.22088/acadpub.BUMS.2.2.148

17 Emaneini M, Jabalameli F, van Leeuwen WB, Beigverdi R. Prevalence of group B Streptococcus in pregnant women in Iran: a systematic review and meta-analysis. Pediatr Infect Dis J. 2018;37 (02):186-190. Doi: 10.1097/INF.0000000000001713

18 Barbaros I, Murat C, Mehmet V, Tekirdag AI, Can K, Sukufe D, et al. The colonization incidence of group B streptococcus in pregnant women and their newborns in Istanbul. Pediatr Int. 2005;47(01): 64-66. Doi: 10.1111/j.1442-200x.2004.02003.x

19 Lu B, Li D, Cui Y, Sui W, Huang L, Lu X. Epidemiology of Group B streptococcus isolated from pregnant women in Beijing, China. Clin Microbiol Infect. 2014;20(06):0370-0373. Doi: 10.1111/ 1469-0691.12416

$20 \mathrm{Kim}$ EJ, Oh KY, Kim MY, Seo YS, Shin J-H, Song YR, et al. Risk factors for group B streptococcus colonization among pregnant women in Korea. Epidemiol Health. 2011;33:e2011010. Doi: 10.4178/epih/e2011010

21 Yang MJ, Sun PL, Wen KC, Chao KC, Chang WH, Chen CY, Wang PH. Prevalence of maternal group $\mathrm{B}$ streptococcus colonization and vertical transmission in low-risk women in a single institute. J Chin Med Assoc. 2012;75(01):25-28. Doi: 10.1016/j. jcma.2011.10.011

22 Joachim A, Matee MI, Massawe FA, Lyamuya EF. Maternal and neonatal colonisation of group B streptococcus at Muhimbili National Hospital in Dar es Salaam, Tanzania: prevalence, risk factors and antimicrobial resistance. BMC Public Health. 2009; 9:437. Doi: 10.1186/1471-2458-9-437

23 Lee WT, Lai MC. High prevalence of Streptococcus agalactiae from vaginas of women in Taiwan and its mechanisms of macrolide and quinolone resistance. J Microbiol Immunol Infect. 2015;48(05): 510-516. Doi: 10.1016/j.jmii.2014.03.002

24 Mohammed M, Asrat D, Woldeamanuel Y, Assegu D. Prevalence of group B Streptococcus colonization among pregnant women attending antenatal clinic of Hawassa Health Center, Hawassa, Ethiopia. Ethiop J Health Dev.. 2012;26(01):36-42

25 Patil K, Singla S, Nagmoti MB, Swamy MK. Group B streptococci colonization in pregnant women: is screening necessary? J South Asian Fed Obstet Gynaecol.. 2013;5:64-7. Doi: 10.5005/jp-journals-10006-1226

26 Collins TS, Calderon M, Gilman RH, Vivar A, Charache P. Group B streptococcal colonization in a developing country: its association with sexually transmitted disease and socioeconomic factors. Am J Trop Med Hyg. 1998;59(04):633-636. Doi: 10.4269/ ajtmh.1998.59.633

27 Costa ALR, Lamy Filho F, Chein MBC, Brito LMO, Lamy ZC, Andrade KL. [Prevalence of colonization by group B Streptococcus in pregnant women from a public maternity of Northwest region of Brazil]. Rev Bras Ginecol Obstet. 2008;30(06):274-280. Doi: 10.1590/s0100-72032008000600002

28 Zusman AS, Baltimore RS, Fonseca SNS. Prevalence of maternal group B streptococcal colonization and related risk factors in a Brazilian population. Braz J Infect Dis. 2006;10(04):242-246. Doi: 10.1590/s1413-86702006000400005

29 Onipede A, Adefusi O, Adeyemi A, Adejuyigbe E, Oyelese A, Ogunniyi T, Group B. Streptococcus carriage during late pregnan- cy in Ile-Ife, Nigeria. Afr J Clin Exp Microbiol.. 2012;13(03): 135-43. Doi: 10.4314/ajcem.v13i3.2

30 Simoes JA, Alves VMN, Fracalanzza SEL, Camargo RPS, Mathias L, Milanez HMBP, Brolazo EM. Phenotypical characteristics of group B streptococcus in parturients. Braz J Infect Dis. 2007;11(02): 261-266. Doi: 10.1590/S1413-86702007000200019

31 Orrett FA. Colonization with Group B streptococci in pregnancy and outcome of infected neonates in Trinidad. Pediatr Int. 2003; 45(03):319-323. Doi: 10.1046/j.1442-200x.2003.01705.x

32 Ji W, Zhang L, Guo Z, Xie Shujin, Yang W, Chen J, et al. Colonization prevalence and antibiotic susceptibility of Group B Streptococcus in pregnant women over a 6-year period in Dongguan, China. PLoS One. 2017;12(08):e0183083. Doi: 10.1371/journal.pone.0183083

33 Khan MA, Faiz A, Ashshi AM. Maternal colonization of group B streptococcus: prevalence, associated factors and antimicrobial resistance. Ann Saudi Med. 2015;35(06):423-427. Doi: 10.5144/0256-4947.2015.423

34 Khoshkhoutabar T, Zand S, Abtahi H, Rafiei M. Frequency and drug resistance of Group B Streptococcus in pregnant women in Markazi Province, Iran. Med Lab J.. 2015;8(04):75-80

35 Mousavi SM, Nasaj M, Hosseini SM, Arabestani MR. Survey of strain distribution and antibiotic resistance pattern of group B streptococci (Streptococcus agalactiae) isolated from clinical specimens. GMS Hyg Infect Control. 2016;11:Doc18. Doi: 10.3205/dgkh000278

36 Daramroodi AK, Keshavarzi F. The investigation of antibiotic resistance and rapid detection of group B Streptococcus (Bca) from vaginal specimens of pregnant women by colony PCR method. J Basic Res Med Sci.. 2018;5(02):27-32. Doi: 10.29252/jbrms.5.2.27

37 Wang P, Ma Z, Tong J, Zhao R, Shi W, Yu S, et al. Serotype distribution, antimicrobial resistance, and molecular characterization of invasive group B Streptococcus isolates recovered from Chinese neonates. Int J Infect Dis. 2015;37:115-118. Doi: 10.1016/j.ijid.2015.06.019

38 Wang S, Li L, Wu B, Wu W. Serotype, genotype, and clinical manifestations of Group B Streptococcus (GBS) isolated from neonates in China. Iran J Pediatr.. 2018;28(01):e14580. Doi: 10.5812/ijp. 14580

39 Hamid ZO, Zaki NH, Ali MR. Prevalence of macrolide resistance genes among Group B Streptococci in pregnant women. Int J Curr Microbiol Appl Sci.. 2015;4(01):419-36

40 Back EE, O'Grady EJ, Back JD. High rates of perinatal group B Streptococcus clindamycin and erythromycin resistance in an upstate New York hospital. Antimicrob Agents Chemother. 2012;56(02):739-742. Doi: 10.1128/AAC.05794-11

41 Matani C, Trezzi M, Matteini A, Catalani C, Messeri D, Catalani C. Streptococcus agalactiae: prevalence of antimicrobial resistance in vaginal and rectal swabs in Italian pregnant women. Infez Med. 2016;24(03):217-221

42 Bolukaoto JY, Monyama CM, Chukwu MO, Lekala SM, Nchabeleng M, Maloba MRB, et al. Antibiotic resistance of Streptococcus agalactiae isolated from pregnant women in Garankuwa, South Africa. BMC Res Notes. 2015;8:364. Doi: 10.1186/s13104-015-1328-0

43 Dogan B, Schukken YH, Santisteban C, Boor KJ. Distribution of serotypes and antimicrobial resistance genes among Streptococcus agalactiae isolates from bovine and human hosts. J Clin Microbiol. 2005;43(12):5899-5906. Doi: 10.1128/JCM.43.12.5899-5906.2005 